\title{
The first record of the female of Idastrandia orientalis (Szombathy 1915) from Singapore, with redescription of the holotype (Araneae: Salticidae)
}

\author{
Takeshi Yamasaki ${ }^{1 *}$, Joseph K. H. Koh ${ }^{2,3} \&$ David J. Court ${ }^{3}$ \\ ${ }^{1}$ Makino Herbarium, Tokyo Metropolitan University, 1-1 Minami-osawa, Hachioji-shi, Tokyo 192-0397, Japan \\ E-mail: k0468874@kadai.jp \\ ${ }^{2}$ National Biodiversity Centre, National Parks Board, Singapore 259569. \\ ${ }^{3}$ Lee Kong Chian Natural History Museum, National University of Singapore, Singapore 117377 \\ *Corresponding author
}

\begin{abstract}
The female of Idastrandia orientalis (Szombathy 1915) is described for the first time, with redescription of the holotype male. Female specimens collected from the type locality share the somatic morphology of the holotype male, especially in the presence of a serrated retrolateral tooth on the chelicerae. On the basis of coloration and external morphological similarities, we conclude that our female specimens are conspecific with Idastrandia orientalis.
\end{abstract}

Key words - Nannenini, taxonomy, jumping spiders, Hungarian Natural History Museum

\section{Introduction}

The genus Idastrandia Strand 1929 (Araneae: Salticidae) is a monotypic genus placed under the tribe Nannenini together with the genera Nannenus and Langerra (Maddison 2015). The species of Nannenini are currently known from only Southeast Asia. Although they share common features such as a fixed embolus and having long macrosetae under tibia I, these morphological characteristics are not considered as synapomorphies (Maddison 2015). However, molecular phylogenetic studies combining several genes support the monophyly of the tribe Nannenini (Bodner \& Maddison 2013; Maddison et al. 2014).

In Singapore, Idastrandia orientalis (Szombathy 1915) was described on the basis of a single male specimen. No additional specimens have been discovered ever since. This paper describes the female for the first time, which is not only new data, but also additional morphological information for this monotypic genus. We also take this opportunity to redescribe Idastrandia orientalis using the holotype male, and extend the diagnosis.

\section{Materials and methods}

The holotype male of Idastrandia orientalis was loaned from the Hungarian Natural History Museum, Budapest (HNHM). Additional specimens were collected in Singapore, and are now part of Koh's personal collection that is destined to be deposited at the Lee Kong Chian Natural History Museum at the National University of Singapore (LKCNHM). Their morphology was examined with a Nikon SMZ1270 microscope. Multi-focused montage images were produced using Helicon Focus ver. 4.2.9 from several series of source images. The source images were obtained by a Canon EOS 60D camera attached to a Nikon SMZ1270. The habitus photo in the field was taken by a Nikon D100 with a Nikon $105 \mathrm{~mm}$ macro lens.

All measurements are given in millimeters. Abbreviations of morphological terms used in the present paper are as follows: ALE, anterior lateral eye; AME, anterior median eye; PLE, posterior lateral eye; PME, posterior median eye; RTA, retrolateral tibial apophysis on palp.

\section{Idastrandia orientalis (Szombathy 1915)}

(Figs. 1-17)

Pseudamycus orientalis Szombathy 1915: 474, f. 5.

Ida-strandia orientalis: Strand 1929: 18 (generic replacement name).

Kolomana orientalis: Roewer 1951: 450 (superfluous generic replacement name).

Idastrandia orientalis: Prószyński 1983: 287, f. 7-10.

Type material examined. Holotype male (HNHM Araneae-5162), Singapore.

Material examined. One female (JK.81.12.13.0004; LKCNHM), Upper Peirce Reservoir (N01 $22^{\prime} 52^{\prime \prime}$ E $103^{\circ} 48^{\prime}$ 37"), Singapore, 13-XII-1981, J. K. H. Koh leg.; 1 female (JK.13.10.01.0002; LKCNHM), Bukit Timah Nature Reserve (N01 $\left.21^{\prime} 22^{\prime \prime} \mathrm{E} 103^{\circ} 47^{\prime} 01^{\prime \prime}\right)$, Singapore, 01-X-2013, J. M. B. Koh leg.

Measurements (Holotype male / 2 females). Total length 4.9 / 5.4-5.7. Carapace length $2.70 / 2.40-2.90$; width $2.27 / 2.15-2.30$. ALE-PLE $1.36 / 1.40-1.43$; ALEPME $0.70 / 0.73-0.75$. Width of eye row I 2.13 / 2.03-2.10; 

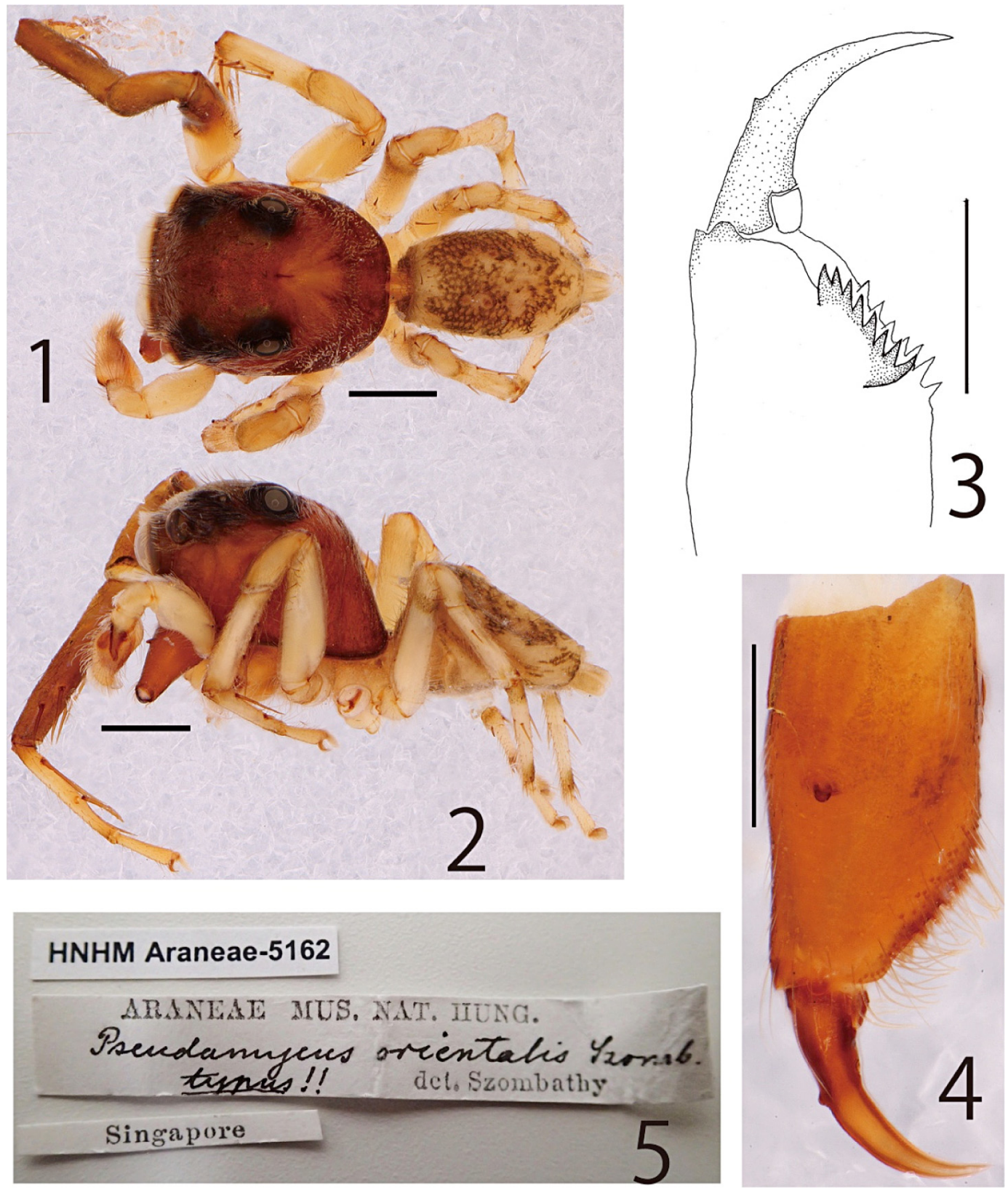

Figs. 1-5. Holotype male of Idastrandia orientalis. 1, habitus, dorsal view; 2, habitus, lateral view; 3, right chelicera and fang, ventral view; 4 , right chelicera and fang, frontal view; 5, labels. Scales $=1 \mathrm{~mm}(1-2) ; 0.5 \mathrm{~mm}(3-4)$.

II $1.80 / 1.70-1.76$; III $1.93 / 1.88-1.93$. Abdomen length 2.07 / 2.80-3.05; width $1.25 / 2.10-2.27$.

Diagnosis. Both sexes can be identified by the highly elevated carapace, and the serrated retromarginal tooth of cheliceral furrow, also mentioned in the original description (Céphalothorax très élevé [Cephalothorax high]). The male can be identified by the elongated bulb with a posterior lobe, the short embolus and the broad RTA of palp. The female can be identified by epigyne with the sclerotized ridge, which is running antero-posteriorly with depression at the posterior end.

Male. Carapace in dorsal view round, but slightly longer than wide (Figs. 1-2). Chelicera bearing seven promarginal teeth and an eight-cusped retromarginal tooth of fang furrow (Fig. 3); one small protuberance located on frontal surface (Fig. 4). Abdomen slender oval (Figs. 1-2).

Palp (Figs. 6-8). Bulb elongated; posterior lobe extending and reaching anterior margin of tibia (Figs. 6-7). 

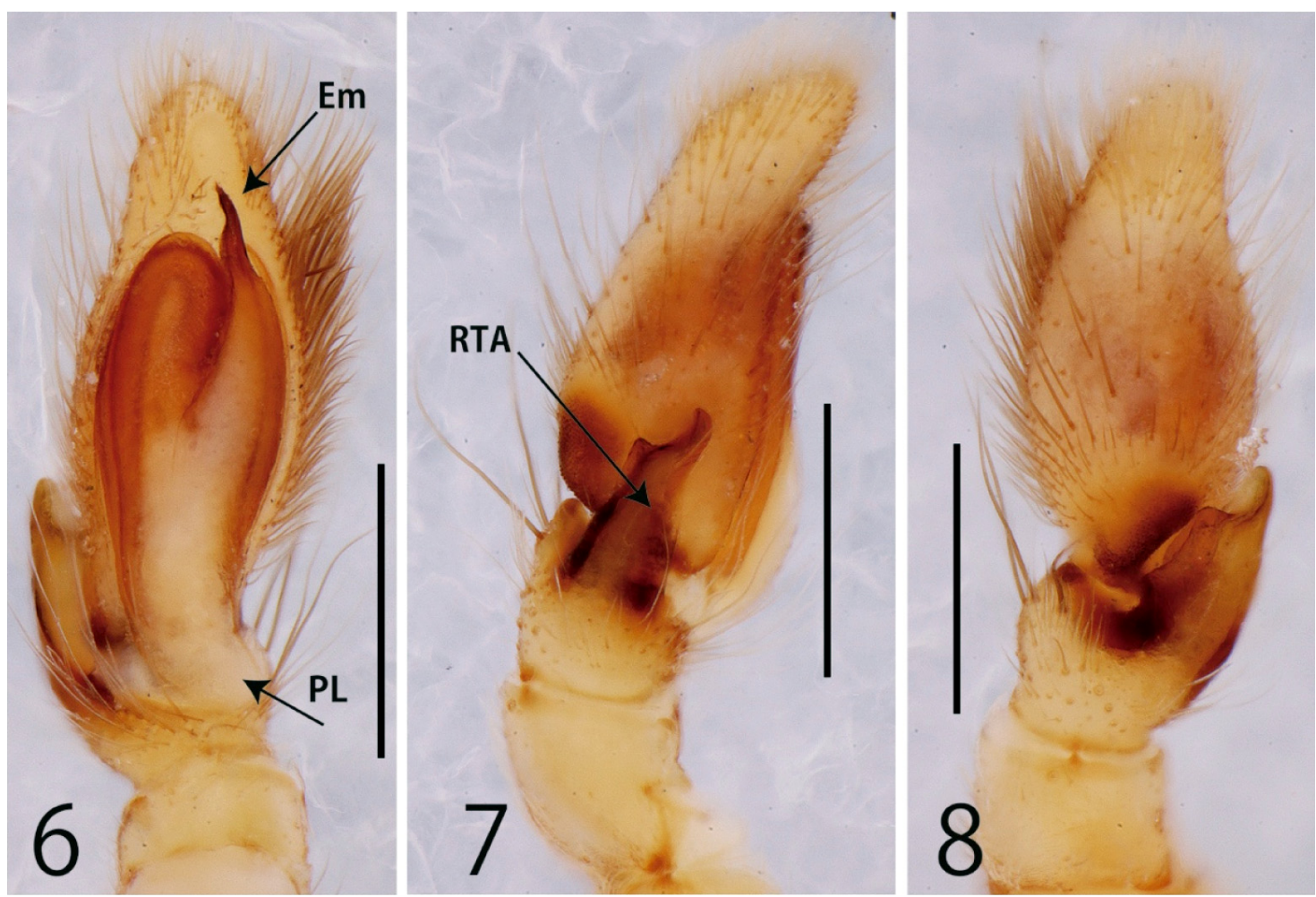

Figs. 6-8. Right male palp of Idastrandia orientalis. 6, ventral view; 7, retrolateral view; 8, dorsal view. Em: embolus; PL: posterior lobe; RTA: retrolateral tibial apophysis. Scale $=0.5 \mathrm{~mm}$.

Seminal duct beginning from base of embolus, and running along margin of bulb, connecting to embolus (Fig. 7). Broad RTA developed and lateral margins curling inwards (Figs. 7-8).

Coloration and setation (Figs. 1-2). Carapace brown, covered with white setae. Chelicera and fang brown (Fig. 4). Abdomen cream, tinged with black, covered with fine setae (Figs. 1-2). Legs cream except brown tibia I and patella I (Figs. 1-2).

Female (Figs. 9-11). Carapace almost same as in male (Figs. 9-10). Chelicera bearing five promarginal teeth and a six- or eight-cusped retromarginal tooth on fang furrow, without small protuberance on frontal surface (Fig. 11). Abdomen oval (Figs. 9-10).

Epigyne with sclerotized ridge running anteroposteriorly, curving outwards; posterior end of sclerotized ridge strongly concaved (Figs. 12-13, 15). Copulatory opening slit-like shape. Copulatory duct very narrow and connecting to round spermatheca (Figs. 12-16).

Coloration and setation almost same as in male (Figs. 910).

Remarks. The label information of the holotype male is shown in Figure 5. Conspecifity of the female specimens with the holotype male is based on the high carapace and the unique serrate retrolateral tooth on the chelicera. The coloration and setation of the male in living condition is shown in Fig. 17.

\section{Acknowledgments}

We would like to thank Dr. László Dányi (HNHM, Hungary) for loaning the type material and two anonymous referees for their critical readings of this manuscript. The field works in Singapore were approved by National Parks Broad under the permission NP/RP1212070-2. The study was supported by JSPS KAKENHI Grant Number 14J04245, Sumitomo Foundation Grant for Basic Science Research Projects No. 130648, and National Biodiversity Honorary Research Fellowship Programme awarded to Joseph K H Koh.

\section{References}

Bodner, M. R. \& Maddison, W. P. 2012. The Biogeography and age of salticid spider radiations (Araneae: Salticidae). Mol. Phylogenet. Evol., 65: 213-240.

Maddison, W. P. 2015. A phylognetic classification of jumping spiders (Araneae: Salticidae). J. Arachnol., 43: 231-291.

Maddison, W. P., Li, D., Bodner, M., Zhang, J., Xu, X., Liu, Q. \& Liu, F. 2014. The deep phylogeny of jumping spiders (Araneae, Salticidae). ZooKeys, 440: 57-87.

Prószyński, J. 1983. Redescriptions of types of Oriental and Australian Salticidae (Aranea) in the Hungarian Natural History Museum, Budapest. Folia Ent. Hung., 44: 283-297.

Roewer, C. F. 1951. Neue Namen einiger Araneen-Arten. Abh. 

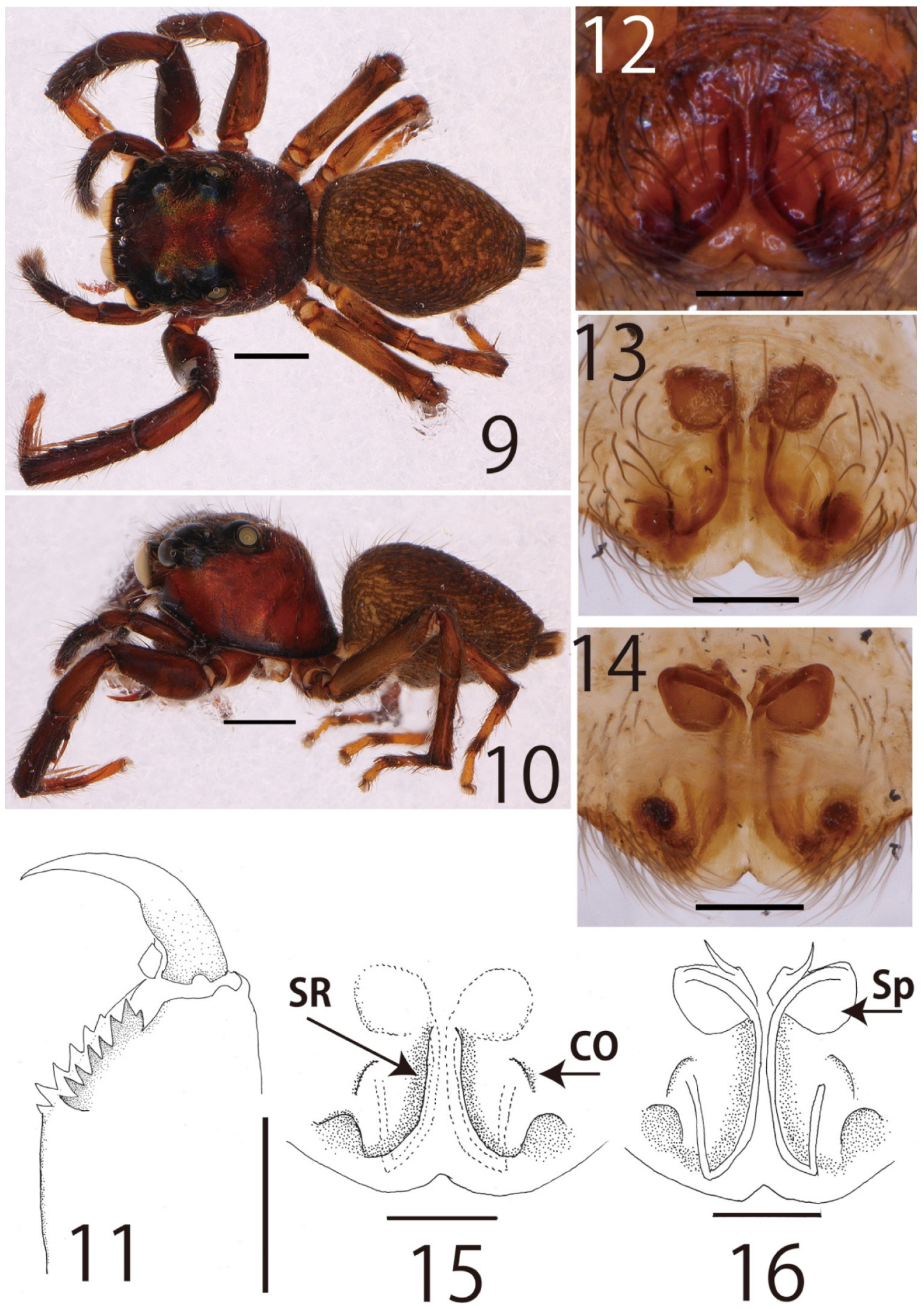

Figs. 9-16. Female of Idastrandia orientalis (JK.13.10.01.0002). 9, habitus, dorsal view; 10, habitus, lateral view; 11, left chelicera and fang, ventral view; 12-13, 15, epigyne, ventral view; 14, 16, epigyne, dorsal view. CO: copulatory opening; Sp: spermatheca; SR: sclerotized ridge. Scales $=1 \mathrm{~mm}\left(9^{-} 10\right) ; 0.5 \mathrm{~mm}(11) ; 0.2 \mathrm{~mm}\left(12^{-}-16\right)$. 


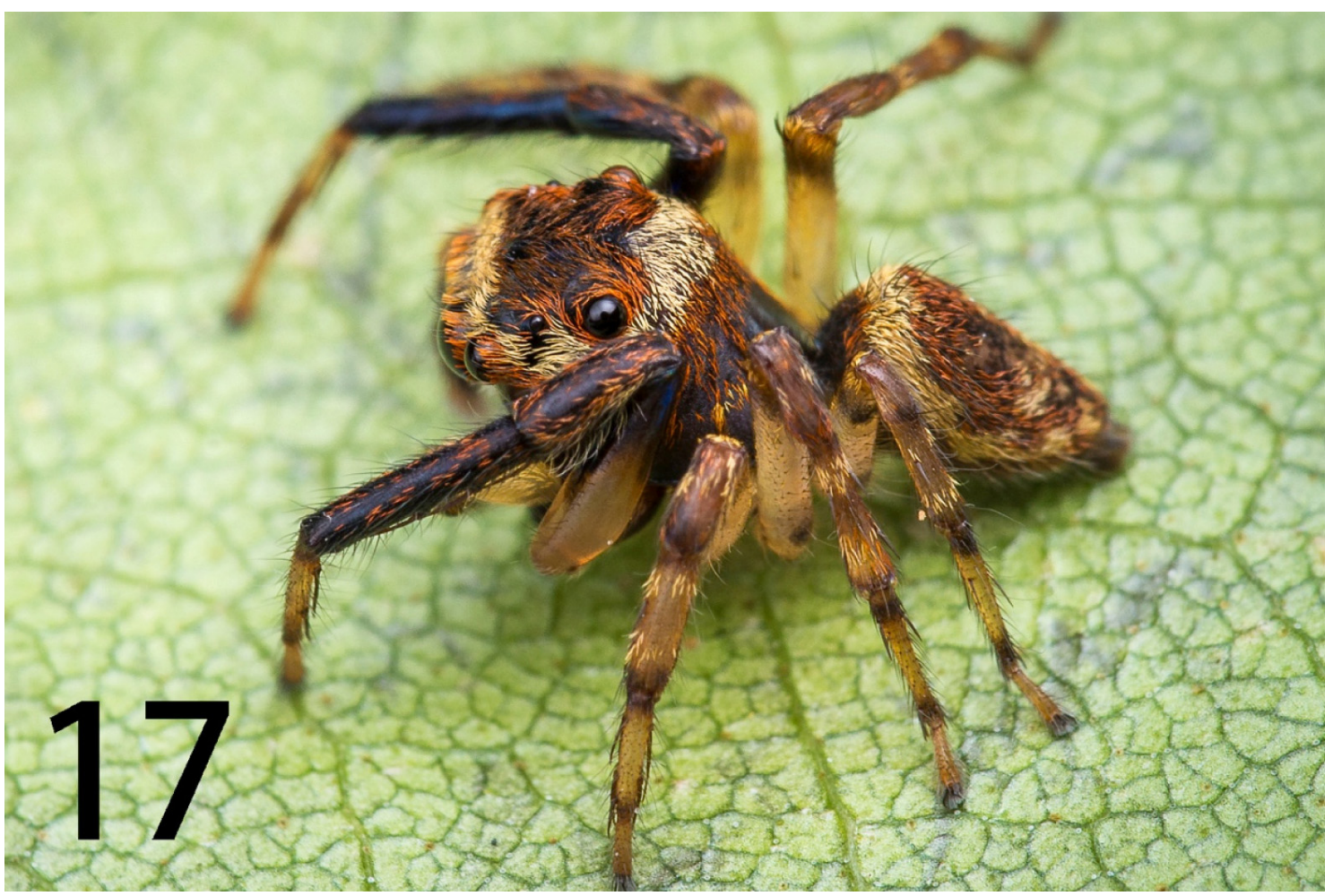

Fig. 17. Male of Idastrandia orientalis in living condition, Bukit Timah Nature Reserve, Singapore. Not examined in the present study. Photo by Joseph K. H. Koh.

Naturwiss. Ver. Bremen, 32: 437-456.

Strand, E. 1929. Zoological and palaeontological nomenclatorical notes. Acta Univ. Latv., 20: 1-29.

Szombathy, C. 1915. Attides nouveaux appartenant aux collections du Musée national hongrois. Annls Hist.-Nat. Mus. Natn. Hung., 13: $468-490$.

Received September 20, 2017 / Accepted October 22, 2017 